\title{
On the Formation and Properties of Globin Plastein
}

\author{
F. R. WILLIAMS and ARTTURI I. VIRTANEN
}

Laboratory of the Foundation for Chemical Research, Biochemical Institute, Helsinki, Finland

T The background to the experiments reported in the present paper is as follows: Some years ago it was demonstrated in this laboratory that the so-called plastein formation by the action of pepsin on the peptic hydrolysate of proteins is due to the enzymatic synthesis of polypeptides ${ }^{1,2}$. The experiments with zein showed that the average molecular weight of the polypeptide precipitate varies quite considerably in different experiments, the values obtained being from two-three thousand to ten thousand and even more. The polypeptide size depends greatly on the conditions (especially $\mathrm{pH}$ ) under which the peptic hydrolysis of proteins is carried out. The amino acid composition of the polypeptide precipitate corresponds, at least to a great extent, to the respective composition of the zein used as starting material. Only the amide content of synthetic polypeptides is lower than in zein, and this differs in different plastein preparations depending on the duration and $\mathrm{pH}$ of the hydrolysis, or, in other words, on the amount of ammonia split off during the hydrolysis from the $\mathrm{CONH}_{2}$-groups of the asparagine and glutamine present in the protein.

The similarity of the amino acid composition of the polypeptide mixture, formed by the action of pepsin, to that of the original protein, together with the high molecular weight of these polypeptides, has raised the question of the extent to which these polypeptides, attached to active groups, can function as catalysts like enzymes. In order to gain information on this question the present study on hemoglobin was undertaken. The aim was to hydrolyze with pepsin the globin prepared from hemoglobin and to examine whether the plastein prepared from this hydrolysate by means of pepsin would combine with the heme group to give a product with an absorption spectrum similar to that of a compound of the hemoglobin type. 


\section{EXPERIMENTAL}

From the washed ox erythrocytes a stroma-free solution of hemoglobin was prepared. Crystallization was effected from $25 \%$ alcohol at $c a .-3^{\circ} \mathrm{C}$ (10 days). The crystals were centrifuged rapidly in the cold, washed with $25 \%$ alcohol and dissolved in a small amount of water. This solution was dialyzed overnight against running tap water and centrifuged clear. Soluble globin was prepared from this solution by the method of Anson and Mirsky ${ }^{3}$. The saltfree solution obtained after dialysis was dried by the lyophilization process and the product remained soluble in water.

It has been shown by earlier work in this laboratory that when using zein the optimal conditions for plastein formation are hydrolysis at $\mathrm{pH} 1-2$ followed by precipitation at pH 44. These conditions were used in the experiments described in the present paper. Three separate hydrolyses of globin were performed.

A $3 \mathrm{~g}$ sample of the globin was dissolved in $400 \mathrm{ml}$ diluted hydrochloric acid at $\mathrm{pH}$ 1.5 and $15 \mathrm{mg}$ crystalline pepsin were added. The solution was incubated at $37^{\circ} \mathrm{C}$ until determinations of the peptide amino nitrogen showed no further hydrolysis of the globin (3-4 days). All determinations of amino nitrogen in these experiments were made by the copper method ${ }^{5}$, and calculated using the factor 0.14 . The average size of the peptides in solution was calculated from determination of the total nitrogen (Kjeldahl) and amino nitrogen (by total hydrolysis) present in the globin preparation, and was found to be 6.4 amino acid residues.

Under reduced pressure the hydrolysate was concentrated almost to dryness. Distilled water was added and the solution again concentrated. This procedure was repeated 5 times before the concentrate was adjusted to $\mathrm{pH} 4$ with $1 \mathrm{~N} \mathrm{NaOH}$. A slight cloudiness was observed and the solution was allowed to stand at room temperature until the next day, when it was centrifuged clear. After 24 hours the solution was still clear and a determination of the amino nitrogen present showed that there had been a negligible loss during the concentration and ensuing operations.

The concentration of total nitrogen in the hydrolysate concentrate was approximately $18 \mathrm{mg} \mathrm{N} / \mathrm{ml}(17.8-18.8 \mathrm{mg} / \mathrm{ml}) .2 \mathrm{mg}$ of crystalline pepsin per $\mathrm{ml}$ was used for precipitation of the plastein, the formation of which was observed to commence almost immediately. The mixture was, however, set aside for 24 hours at room temperature and the precipitate was then separated by centrifugation and washed with a small amount of water. A second and smaller precipitate had separated $\mathbf{4 8}$ hours later and was collected as before.

Nitrogen estimations on the precipitates showed that they contained a little more than $12 \%$ total $\mathrm{N}(12.17-12.33 \%)$, and more than $1.1 \%$ amino $\mathrm{N}(1.11-1.20 \%)$ of dry matter, the latter figure being equivalent to more than $9 \%$ of the total $\mathrm{N}(9.0-$ $9.7 \%$ ). The average size of the peptides constituting the plastein was thus approximately 9 amino acids. The weight of plastein obtained was approximately $10 \%$ of the weight of globin $(9.28-10.98 \%)$ whereas the loss of amino $\mathrm{N}$ through pepsin at $\mathrm{pH} 4$ was approximately $13 \%(12.00-13.44 \%)$ of the total $\mathrm{N}$ present in the hydrolysate concentrate.

It was thus evident that the plastein synthesized under these conditions consisted of smaller peptides than did the zein plasteins which had been synthesized earlier in this laboratory, and which, as raw plasteins, had been found to contain approximately $3-5 \%$ of their total $\mathrm{N}$ as amino $\mathrm{N}$ corresponding to an average peptide size of about $25-30$ peptides. By careful extraction with water a number of small peptides could be removed from these zein plastein precipitates after which the average size of the remaining poly-

Acta Chem. Scand. 7 (1953) No. 2 
peptides corresponded to about 40-peptides. No attempts were made with the globin plasteins to separate the mixture of peptides into fractions containing different amounts of amino $\mathrm{N}$.

As a basis for comparison between the relative average sizes of the plasteins synthesized from different proteins under similar conditions, samples of egg albumin and zein were hydrolyzed for 4 days using the same dilution, $\mathrm{pH}$, and pepsin concentration as for the globin hydrolyses. The figures for the average size of the peptides in the hydrolysates were respectively 6.4 for the egg albumin hydrolysate and 8.3 for the zein hydrolysate (after allowing for $2 \%$ insoluble material present in the zein sample used). The hydrolysates were concentrated and adjusted to pH 4 in the same manner as were the globin hydrolysates and the plastein formation was made from solutions containing respectively 17.2 and $17.4 \mathrm{mg} \mathrm{N} / \mathrm{ml}$. The egg albumin plastein contained $13.9 \%$ total $\mathrm{N}$ and $0.92 \%$ amino $\mathrm{N}$ of dry matter (equivalent to $6.6 \%$ of total nitrogen and corresponding to a peptide size of between 11 and 12 amino acids) and the weight of the precipitate was $14.5 \%$ of the original protein. For the zein plastein the corresponding nitrogen figures were $13.3 \%$ and $0.49 \%$ (equivalent to $3.7 \%$ of total nitrogen and a peptide size of 21 22 amino acids) and the weight was $16.4 \%$ of the original protein.

\section{RESULTS AND DISCUSSION}

As was stated earlier in this paper, attempts were made to produce a reaction between the globin plastein and a freshly prepared solution of heme. This latter solution was prepared in $1 \mathrm{M} \mathrm{K}_{2} \mathrm{HPO}_{4}$ and was diluted 50 times in order to give a preparation suitable for readings with the Beckman spectrophotometer. The aqueous solution of plastein containing $5.5 \mathrm{mg}$ dry material per $100 \mathrm{ml}$ at $\mathrm{pH} 5.7$ was mixed with the heme solution in the proportion of $1: 2$, the $\mathrm{pH}$ of the mixture being 8.6. The spectrum obtained for this solution was identical to that given by a mixture of 2 parts of the heme solution with 1 part of distilled water. Under similar conditions the spectrum obtained by mixing the heme solution and a solution of the soluble globin possessed the typical maxima of a compound of the hemoglobin type. Thus no compound resembling hemoglobin was formed from globin plastein and heme.

The plastein yield from the peptic hydrolysate of globin was smaller than from the corresponding hydrolysate of zein. The decrease of amino nitrogen in the plastein synthesis was distinct even in the former case. It is of interest that the average peptide size of globin plastein corresponded to only about 9-peptides. Although this would probably have risen through the extraction of the lower peptides, it is, however, at least obvious that no large amounts of high-molecular peptides are formed from globin plastein. Thus a distinct difference exists between the zein and globin hydrolysates in regard to the polypeptide synthesis. This synthesis proceeds gradually in the zein hydrolysate $^{1,2}$, small polypeptides being first formed during the rapid decrease of amino nitrogen and remaining in the solution. The synthesis continues as the small

Acta Chem. Scand. 7 (1953) No. 2 
polypeptides join to bigger ones whereby an intensive precipitation takes place. Both reactions can be so rapid that they are difficult to distinguish from each other but when they proceed at a slower rate they can be distinguished. In a previous experiment, in which the average molecular size of the zein hydrolysate corresponded to 5-peptides, only $2.8 \%$ of the total $\mathrm{N}$ of the hydrolysate was precipitated by pepsin at $\mathrm{pH} 4$ during an hour, while the decrease of amino nitrogen was $22.9 \%$ of the amino nitrogen of the hydrolysate. The average peptide size of the solution rose from 5-peptides to about 12-peptides. In 22 hours $19.0 \%$ of the total $N$ of the solution was precipitated. The average peptide size of the precipitate corresponded to about 37-peptides. The small plastein precipitate formed during 1 hour also had the same peptide size. The growth of the polypeptides during the reaction becomes evident from this experiment. The small peptide size of the plastein precipitate obtained from globin hydrolysate can perhaps be explained by assuming that the relatively low-molecular polypeptides, formed at the start of the synthesis, are so difficultly soluble that they are removed from the solution by precipitation. The continuation of the synthesis is thus prevented and no highmolecular peptides are formed. The structure of the peptides formed from different proteins. in peptic hydrolysis would thus determine the chain length of the polypeptides formed in the so-called plastein synthesis.

\section{SUMMARY}

A raw plastein has been prepared from soluble globin. The average peptide size is smaller than those obtainable from zein and egg albumin under similar conditions. No reaction between globin plastein solution and a solution of heme in $\mathrm{K}_{2} \mathrm{HPO}_{4}$ buffer could be detected with the Beckman spectrophotometer. In the discussion, suggestions are put forward to account for the small peptide size of the globin plastein.

\section{REFERENCES}

1. Virtanen, A. I., Kerkkonen, H. K., Laaksonen, T., and Hakala, M. Acta Chem. Scand. 3 (1949) 520.

2. Virtanen, A.I., Kerkkonen, H. K., Hakala, M., and Laaksonen, T. Naturwissenschaften 37 (1950) 139.

3. Anson, M. L., and Mirsky, A. E. J. Gen. Physiol. 13 (1930) 469.

4. Virtanen, A. I., Laaksonen, T., and Kantola, M. Acta Chem. Scand. 5 (1951) 316.

5. Kerkkonen, H. K. Acta Chem. Scand. 2 (1948) 518.

Received December 1, 1952.

Acta Chem. Scand. 7 (1953) No. 2 